\title{
Redefining micrometastasis in prostate cancer - a comparison of circulating prostate cells, bone marrow disseminated tumor cells and micrometastasis: Implications in determining local or systemic treatment for biochemical failure after radical prostatectomy
}

\author{
N.P. MURRAY ${ }^{1-3}$, E. REYES ${ }^{1}$, P. TAPIA ${ }^{4}$, L. BADINEZ ${ }^{5}$, N. ORELLANA ${ }^{1}$, C. FUENTEALBA $^{1}$, \\ R. OLIVARES ${ }^{1}$, J. PORCELL ${ }^{1}$ and R. DUEÑAS ${ }^{1}$ \\ ${ }^{1}$ Hospital Carabineros of Chile, Nunoa, Santiago; ${ }^{2}$ Circulating Tumor Cell Unit, Faculty of Medicine, University Mayor, \\ Las Condes, Santiago; ${ }^{3}$ Institute of Bio-Oncology, Providencia, Santiago; ${ }^{4}$ Faculty of Medicine, \\ Catholic University of Chile, Santiago; ${ }^{5}$ Arturo López Pérez Foundation, Providencia, Santiago, Chile
}

Received May 6, 2012; Accepted June 26, 2012

DOI: $10.3892 / \mathrm{ijmm} .2012 .1071$

\begin{abstract}
The presence of cells positive for cytokeratins or prostate-specific antigen (PSA) in bone marrow aspirates (BMAs) has been used to indicate the presence of micrometastasis. The aim of this prospective study of prostate cancer patients was to determine the presence of prostate cells in blood and BMAs and to compare them with bone marrow biopsy touch prep samples. The results indicated that there was a satisfactory concordance between circulating prostate cells (CPCs) in blood and disseminated tumor cells (DTCs) in BMAs for all Gleason scores $(\kappa>0.50)$. However, neither were concordant with the presence of prostate cells in bone marrow biopsies except for high-grade tumors, Gleason 8 and 9. Phenotypic characteristics of CPCs and DTCs were identical $(\kappa>0.9)$ but were different than cells detected in bone marrow biopsies $(\kappa<0.2)$. The expression of matrix metalloproteinase-2 (MMP-2) in bone marrow biopsies was positively associated with the Gleason score (trend Chi-squared <0.05) and may explain the differences between the presence of DTCs and the presence of prostate cells in bone marrow biopsies. If the presence of DTCs was used to indicate micrometastatic disease, $20 \%$ of patients would be misclassified compared to micrometastasis defined as patients with a positive biopsy. This may have clinical implications for patients with low-grade tumors.
\end{abstract}

Correspondence to: Professor Nigel P. Murray, Circulating Tumor Cell Unit, Faculty of Medicine, University Mayor, Las Condes, Santiago, Chile

E-mail: nigelpetermurray@gmail.com

Key words: circulating prostate cells, disseminated tumor cells, micrometastasis, bone marrow, prostate cancer

\section{Introduction}

In prostate cancer the bone marrow is the most common site involved by metastatic tumors. The diagnosis of metastatic involvement of bone marrow may therefore have a profound effect on the prognosis and treatment of the individual patient. However, the bone marrow may be involved by the tumor without any abnormalities recognized in conventional imaging studies, bone scans, serum biochemistry and/or hematological parameters. Biochemical failure after radical prostatectomy is defined by the NCCN 2012 guidelines (1) as a serum prostatespecific antigen (PSA) $>0.2 \mathrm{ng} / \mathrm{ml}$, with patients having a $100 \%$ (95\% CI, 87-100) 3-year risk of PSA progression (2). However, in men with biochemical failure after radical prostatectomy for prostate cancer and with a negative bone scan, treatment is often empirically based.

The presence of PSA-positive cells in bone marrow aspirates (BMAs) has been used to indicate the presence of micrometastasis. There is an association with tumor stage, Gleason score and time to biochemical failure (3-6). However, these cells may not represent true micrometastasis (7) and may have more in common with circulating prostate cells (CPCs) detected in the blood. The presence of disseminated tumor cells (DTCs) when used to define systemic dissemination after biochemical failure has clinical importance and is an indication for the use of systemic therapy.

BMAs and bone marrow trephine biopsies are considered complementary as diagnotic tests for the presence of micrometastatic involvement, and the use of trephine biopsies is particularly important in cases where an adequate aspirate cannot be obtained due to bone marrow fibrosis or densely packed bone marrow by tumor cells $(8,9)$. Fibrosis is considered slightly increased in bone marrow biopsy specimens in prostate cancer in comparison to other types of solid tumors (10).

The aim of this study was to compare the concordance between the presence of CPCs and DTCs and micrometastasis 
in patients with prostate cancer and their association in lowgrade and high-grade tumors. The phenotypic classification of the cells using monoclonal antibodies against CD82 (a tumor-suppressor gene product), matrix metalloproteinase-2 (MMP-2; involved in dissemination and implantation of tumor cells) and HER-2 expression (a marker of the resistence to androgen blockade) were also investigated. We aimed to ascertain whether DTCs truly indicate micrometastasis and if they exhibit the same phenotypic characteristics as prostate cells identified in bone marrow fragments. We also aimed to verify whether they are CPCs detected in bone marrow rather than blood. We evaluated the clinical implications this may have if DTCs rather than micrometastasis are used to define systemic failure after radical prostatectomy and possible theoretical consequences on treatment decisions.

\section{Patients and methods}

All males with histologically confirmed prostate cancer treated at the Hospital Carabineros of Chile, the Hospital Dipreca, Institute of Bio-Oncology and the Institute of Radiotherapy, INRAD, Santiago, Chile and referred to the Institute of Bio-Oncology between January 2008 and September 2011 and fulfilling inclusion criteria were enrolled in the study. Ten women requiring blood and bone marrow tests for hematological disorders were included as controls.

For each patient the following clinical details were registered: age, total serum PSA at the time of sampling, stage according to the UICC TNM system (2002), 6th edition and Gleason score.

The inclusion criteria were as follows. Patients i) had biopsy confirmed prostate cancer, ii) were treated by radical prostatectomy, iii) had treatment with or without androgen blockade, iv) were enrolled at least 6 months post prostatectomy, v) had negative bone scan and vi) provided written informed consent.

Blood samples. After written informed consent a 4-ml blood sample was collected in EDTA-containing Vacutainer ${ }^{\circledR}$ tubes (Becton-Dickinson). Samples previously stored at $4^{\circ} \mathrm{C}$ were processed within $48 \mathrm{~h}$. The samples were layered onto $2 \mathrm{ml}$ Histopaque $1.077^{\circledR}$ (Sigma-Aldrich) at room temperature, and the mononuclear cells were obtained according to the manufacturer's instructions and finally washed 3 times in phosphate-buffered saline $\mathrm{pH} 7.4$ (PBS). The pellet was re-suspended in $100 \mu \mathrm{l}$ of autologous plasma and $25 \mu \mathrm{l}$ was used to prepare each silanized slide (Dako, USA). The slides were air dried for $24 \mathrm{~h}$ at room temperature and finally fixed in a solution of $70 \%$ ethanol, $5 \%$ formaldehyde and $25 \%$ PBS for 5 min and then washed 3 times with PBS.

Bone marrow. BMA and biopsy samples were obtained from the posterior superior iliac crest. Patients were sedated with 5-15 $\mathrm{mg}$ of intravenous midazolam and the procedure was carried out using 5-10 $\mathrm{ml}$ of $2 \%$ lidocaine local anesthetic. The aspiration sample was processed as described for the blood samples, except that the fat was removed by centrifugation and discarded prior to gel differential centrifugation. The bone marrow biopsy sample was used to make 3 touch-preps using silanized slides (Dako) and both types of samples were fixed as previously described. Touch preps were used instead of traditional biopsy analysis, owing to the possible destruction of epitopes during the process of the bone marrow biopsy sample decalcification.

Immunocytochemistry. Monoclonal antibodies directed against PSA clone 28A4 (Novacastro, UK) at a concentration of $2.5 \mu \mathrm{g} / \mathrm{ml}$ were used to detect prostate cells, and were identified using a detection system based on alkaline phosphatase-antialkaline phosphatase (LSAB2; Dako) with New Fuchsin as the chromogen (according to the manufacturer's instructions). To permit the rapid identification of positive cells no counterstaining was carried out with Mayer's hematoxylin. Levisamole (Dako) was used as an inhibitor of endogenous alkaline phosphatase, with positive and negative controls. Positive samples underwent a second stage of processing, using the monoclonal antibody against CD82 or MMP-2 or HER-2 (HercepTest ${ }^{\circledR}$ ) and a system of detection based on peroxidase (LSAB2; Dako) with DAB (Dako) as the chromogen (according to the manufacturer's instructions). Endogenous peroxidase was inhibited by a commercial inhibitor (Dako). Immunocytochemistry was carried out at room temperature.

Definition of a positive sample. The definition of a CPC was based on the criteria of ISHAGE 1999 (11): the morphology of a cell with a nucleus and cytoplasm exhibiting positivity for PSA. The definition of a DTC was similar with the exception that the cell was present in the BMA and/or present in the touch prep of the biopsy sample, but not in the microfragments. Micrometastasis was defined as bone marrow fragments consisting of cells immunostaining positive for PSA (Fig. 1A-F).

Immunophenotype. CD82 expression was scored using a semiquantative scale (Fig. 2A-E): 0, no expression; 1+, part of the cell membrane is CD82 positive; $2+$, all of the cell membrane weakly expresses CD82; $3+$, all of the cell membrane strongly expresses CD82. Samples with $10 \%$ of cell staining 2+ and/or $3+$ were considered positive for CD82 expression (18). MMP-2 expression was scored using a semi-quantative scale. A sample containing $>10 \%$ of cells positive for MMP-2 was considered positive (12) (Fig. 3A-D). HER-2-positive cells were classified according to the HercepTest ${ }^{\circledR}$ scale for breast cancer and approved by the FDA. A score of $2+$ or $3+$ was classified as positive and 0 or $1+$ as negative according to the criteria of Osman et al (13) (Fig. 4A-C).

Definition of biochemical failure. Biochemical failure was defined according to recommendations of the NCCN 2012 guidelines as a serum PSA $>0.2 \mathrm{ng} / \mathrm{ml}$.

Definition of type of relapse, local or systemic. Micrometastasis or systemic relapse was defined as the presence of fragments positive for PSA irrespective of the presence or absence of circulating cells in the blood or bone aspirate. Local recurrence was defined as the presence of negative fragments with the absence of prostate cells in the blood or bone marrow. Local recurrence with a risk of micrometastasis was defined as the presence of negative fragments but with circulating cells in the blood and/or aspirate samples. For each specimen photomicro- 

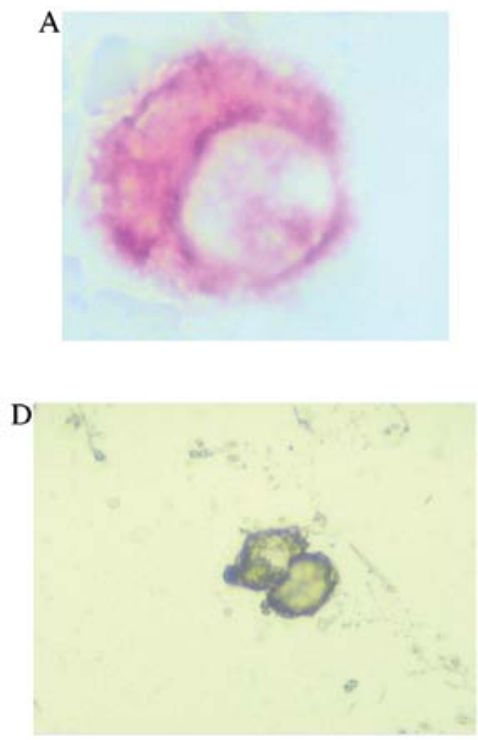
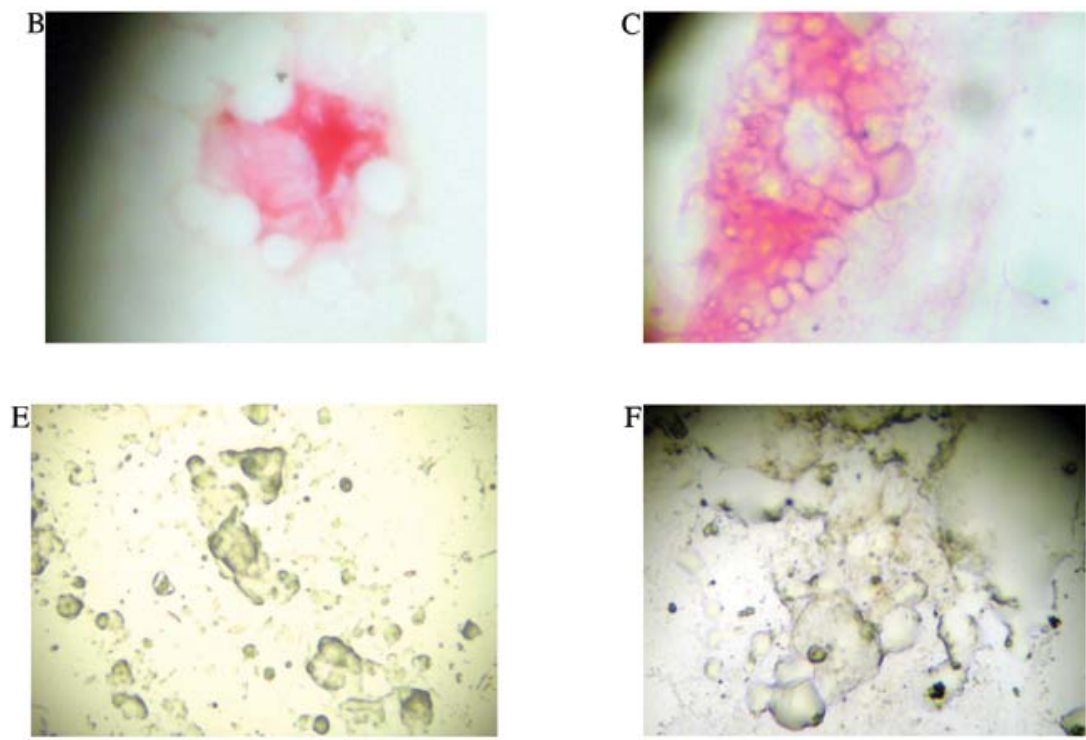

Figure 1. (A) Circulating prostate cell positive for prostate-specific antigen. (B) Disseminated tumor cell positive for prostate-specific antigen. (C) Prostatespecific antigen-positive micrometastasis. (D) Leukocytes negative for prostate-specific antigen. (E) Bone marrow aspirate negative for prostate-specific antigen. (F) Bone marrow biopsy negative for prostate-specific antigen.
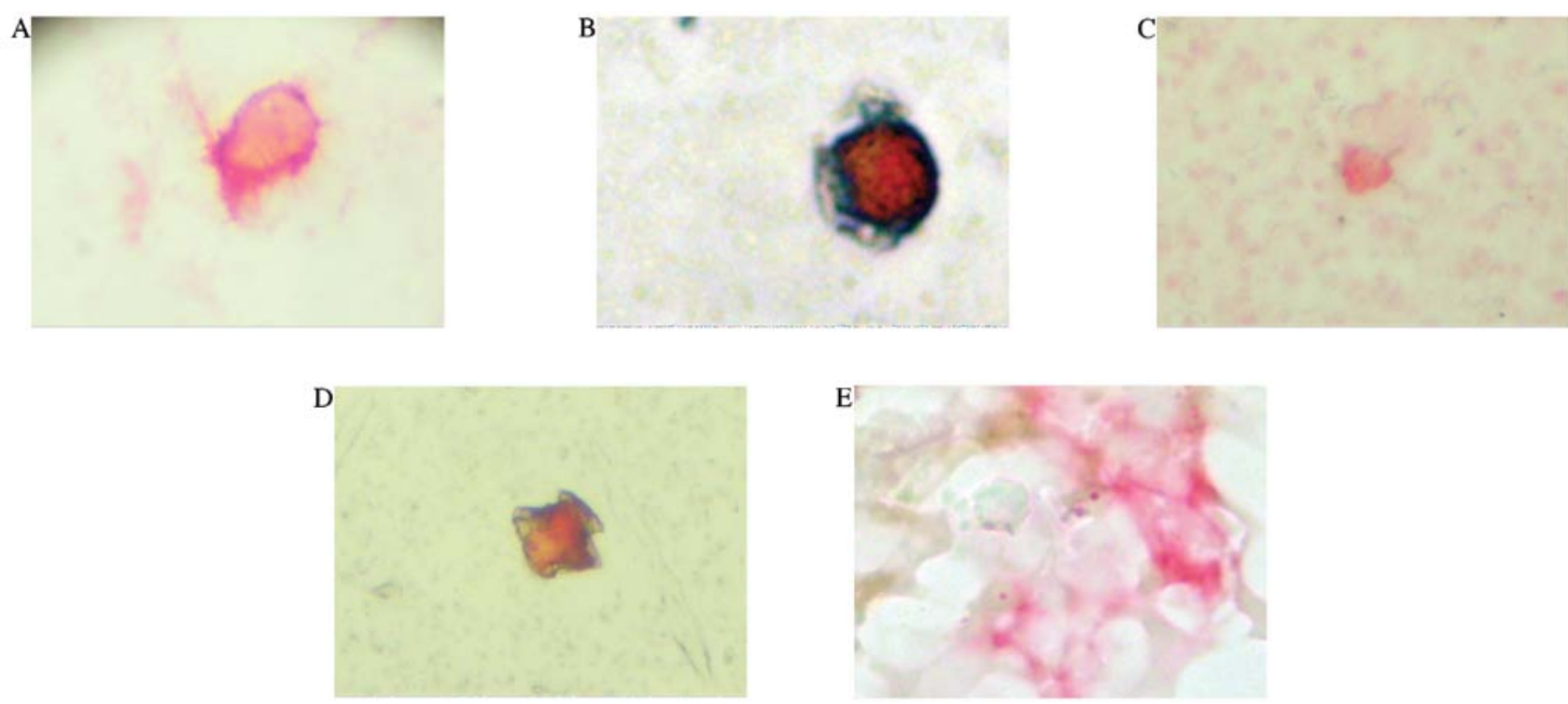

Figure 2. (A) Circulating prostate cell positive for prostate-specific antigen and negative for CD82. (B) Circulating prostate cell positive for prostate-specific antigen and positive for CD82. (C) Disseminated tumor cell positive for prostate-specific antigen and negative for CD82. (D) Disseminated tumor cell positive for prostate-specific antigen and positive for CD82. (E) Micrometastasis positive for prostate-specific antigen and negative for CD82.

graphs were captured with a digital camera, Samsung Digimax D73, and processed with the Digimax program for Windows 98.

Ethical considerations. The study was carried out in full accordance with the Declaration of Helsinki and the Hospital Ethics Committees.

Statistical analysis. Descriptive statistics were used for demographic variables, expressed as the mean \pm standard deviation in the case of continuous variables with a normal distribution. In the event of asymmetrical distribution the median and interquartile range (IQR) values were used. Non-contiguous variables were presented as frequencies. The Student's t-test was used to compare continuous variables with a normal distribution and Chi-square, Kruskal-Wallis and log regression for the differences in frequency. The kappa test was used to analyze concordance.

\section{Results}

Table I shows the demographic characteristics of the 185 men who participated in the study. The presence of CPCs in BMAs and in bone marrow of prostate cancer patients was analyzed by determining PSA protein expression. CPCs were detected in $62.7 \%$, DTCs in $62.2 \%$ and micrometastasis in $71.4 \%$ of the patients. 

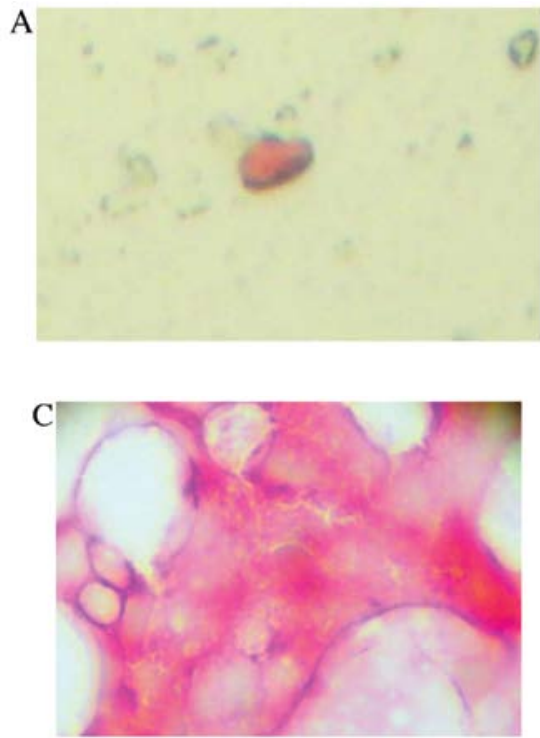
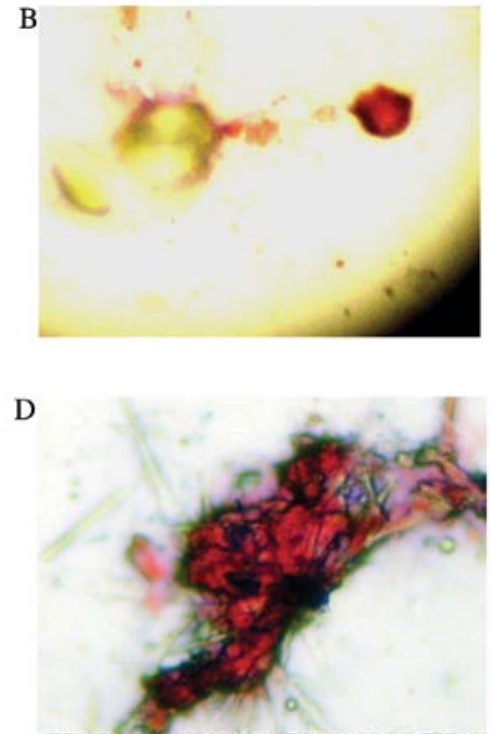

Figure 3. (A) Circulating prostate cell positive for prostate-specific antigen and positive for MMP-2. (B) Disseminated tumor cell positive for prostate-specific antigen and positive for MMP-2. (C) Micrometastasis positive for prostate-specific antigen and negative for MMP-2. (D) Micrometastasis positive for prostatespecific antigen. Borders MMP-2-positive.

A

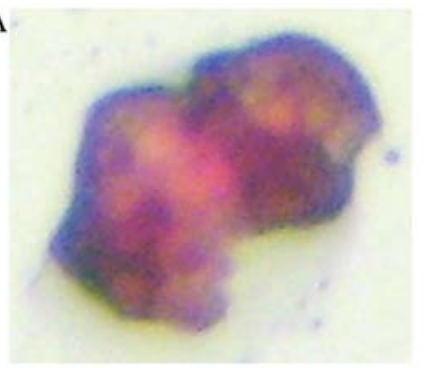

B

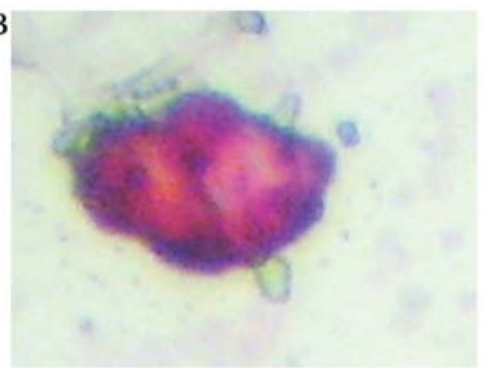

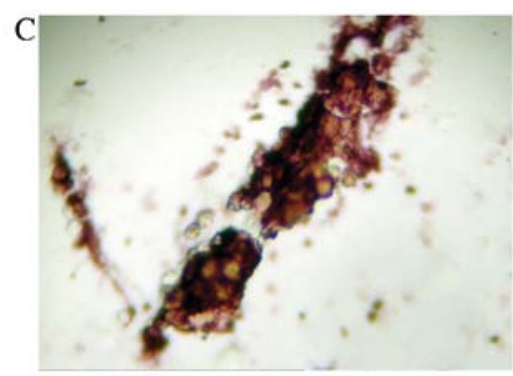

Figure 4. (A) Circulating prostate cell positive for prostate-specific antigen and positive for HER-2. (B) Disseminated tumor cell positive for prostate-specific antigen and positive for HER-2. (C) Micrometastasis positive for prostate-specific antigen and positive for HER-2.

Table I. Demographic characteristics of the study group.
No. of patients, $n$

185

Mean age $\pm S D$, years

$72.2 \pm 9.0$

Median serum PSA (IQR), ng/ml

Median Gleason score (IQR)

$1.32(0.40-5.77)$

Median time from diagnosis (IQR), years

Detection of prostate cells, \% (n)

CPCs

DTCs

$71.4(132)$

Micrometastasis

$81.1(150)$

Post prostatectomy, \% (n)
IQR, interquartile range; CPCs, circulating prostate cells; DTCs, disseminated tumor cells.

Table II shows the PSA protein expression in cells present in blood, BMA and biopsy of cancer patients in comparison with the Gleason score. There was no difference in the detection of cells in relation to age or serum PSA levels or the time from diagnosis to test time. Patients with higher Gleason scores had significantly higher stage disease. There were no differences in the frequency of detection of CPCs and DTCs with regards to the Gleason score. However, the frequency of detection of micrometastasis was significantly lower in patients with Gleason 4 in comparison with higher Gleason scores (Kruskal-Wallis, $\mathrm{P}<0.001$ ).

Table III shows the expression of the markers MMP-2, the tumor suppressor CD82 and HER-2 in patients positive for prostate cells in blood $(n=116)$, BMAs $(n=115)$ and bone marrow biopsy $(n=132)$. MMP-2 expression was commonly limited to the edge of the bone marrow fragment (Fig. 3D).

Table IV shows the concordance among CPCs, DTCs and micrometastasis using kappa statistics. For all Gleason scores there was moderate to good concordance between the detection of CPCs and DTCs. There was low concordance between CPCs and micrometastasis in patients with Gleason 4-7 but moderate concordance in patients with Gleason 8 and 9. There was good concordance between DTCs and micrometastasis in patients with Gleason 4,8 and 9 but low concordance with Gleason 5, 6 and 7. 
Table II. Demographic variables according to Gleason score.

\begin{tabular}{|c|c|c|c|c|c|}
\hline & Gleason 4 & Gleason $5+6$ & Gleason 7 & Gleason $8+9$ & P-value \\
\hline No. of patients, $n$ & 28 & 106 & 31 & 20 & \\
\hline Mean age $\pm \mathrm{SD}$, years & $71.1 \pm 8.7$ & $73.2 \pm 9.4$ & $70 \pm 8.9$ & $71.7 \pm 6.7$ & $\mathrm{NS}^{\mathrm{e}}$ \\
\hline Median serum PSA (IQR), ng/ml & $1.0(0.5-4.8)$ & $1.68(0.5-5.5)$ & $0.57(0.1-10.0)$ & $1.68(0.32-28.7)$ & $\mathrm{NS}^{\mathrm{f}}$ \\
\hline Median stage (IQR) & $2(1-2)^{\mathrm{a}-\mathrm{c}}$ & $3(2-3)^{\mathrm{a}, \mathrm{d}}$ & $3(2-3)^{b}$ & $3(3-4)^{\mathrm{c}, \mathrm{d}}$ & $\begin{array}{c}\quad<0.001^{\mathrm{a}-\mathrm{a}, \mathrm{f}} \\
\quad<0.001^{\mathrm{b}-\mathrm{b}, \mathrm{f}} \\
\quad<0.001^{\mathrm{c}-\mathrm{c}, \mathrm{f}} \\
<0.002^{\mathrm{d}-\mathrm{d}, \mathrm{f}}\end{array}$ \\
\hline $\begin{array}{l}\text { Median time from diagnosis } \\
\text { (IQR), years }\end{array}$ & $2(1-4)$ & $4(1-8)$ & $3(1-5)$ & $2(1-5)$ & $\mathrm{NS}^{\mathrm{f}}$ \\
\hline \multicolumn{6}{|l|}{ Presence of prostate cells, \% (n) } \\
\hline $\mathrm{CPCs}$ & $46.4(13)$ & $63.2(67)$ & $64.5(20)$ & $80(16)$ & $\mathrm{P}=0.0123^{\mathrm{g}}$ \\
\hline DTCs & $35.7(10)$ & $65.1(69)$ & $67.7(21)$ & $75(15)$ & $\mathrm{P}=0.015^{\mathrm{g}}$ \\
\hline Micrometastasis & 32.1 & $77.4(82)$ & $77.4(24)$ & $85(17)$ & $\mathrm{P}=0.001^{\mathrm{g}}$ \\
\hline Prostatectomy \% (n) & $82 \quad(23)$ & $75.5(80)$ & $90.3(28)$ & $95(19)$ & $\mathrm{NS}^{\mathrm{f}}$ \\
\hline
\end{tabular}

${ }^{\mathrm{e}} \mathrm{ANOVA},{ }_{\mathrm{f}}$ Kruskal-Wallis, ${ }^{\mathrm{g}} \mathrm{Chi}-\mathrm{squared} \log$ regression. IQR, interquartile range; CPCs, circulating prostate cells; DTCs, disseminated tumor cells; NS, not significant.

Table V shows the concordance among CPCs, DTCs and micrometastasis for the expression of MMP-2, CD82 and HER-2, respectively. There was complete concordance for the expression of HER-2. MMP-2 was concordant with CPCs and DTCs, but neither was concordant with micrometastasis; a similar result was found for the CD82 expression for Gleason 4 and 5 .

We aimed to evaluate the clinical implications for defining micrometastasis using DTCs vs. micrometastasis (Table VI). Of the total population of 185 men, 13 were positive for DTCs and negative for micrometastasis and 20 were negative for DTCs and positive for micrometastasis. Thus, $17.8 \%$ of cases were misclassified when only DTCs were used to define micrometastasis. Of 115 men with biochemical failure, 7 were positive for DTCs and negative for micrometastasis and 16 were negative for DTCs and positive for micrometastasis representing a misclassification of $20 \%$ of the cases.

\section{Discussion}

This study analyzed the presence of prostate cells in BMAs and biopsy samples and compared their presence and phenotypic characteristics with those of CPCs found in the blood of men with histologically confirmed prostate cancer.

There was no relation with age, serum PSA level or from the time of diagnosis as previously reported (5), and the finding that patients with higher Gleason scores had cancer of a more advanced stage is consistent with the natural history of the disease.

The detection of CPCs and DTCs were independent of the Gleason score suggesting they may be similar in nature (i.e., circulating tumor cells), especially since the presence of micrometastasis was significantly lower in low-grade Gleason 4 tumors.

There was a good concordance between the presence of CPCs and DTCs for all Gleason scores, differing from that of micrometastasis. There was a low concordance between CPCs and micrometastasis except for high-grade Gleason 8 and 9 tumors. This suggests that they represent different types of cells, that micrometastasis is not necessarily associated with actively disseminating cells (CPCs). CPCs may have disseminated from the local disease that is confirmed to the prostate bed or lymph nodes or from systemic bone disease. The presence of CPCs alone does not allow the differentiation between local relapse and systemic relapse. The low concordance between DTCs and micrometastasis for patients with Gleason 5, 6 and 7 suggests there is a difference in their physiological/oncological role. In high-grade Gleason 8 and 9 there was good concordance which may be explained on the basis of rheological studies and the nature of the test itself. Research (5) has shown that prostate cancer micrometastasis has a low proliferation index thus it would be expected that the cells remain adherent to the endosteum and are not present in the intertrabecular spaces, that is the results are usually aspirate-negative but biopsy-positive. This suggests that BMAs may not truly represent micrometastatic disease due to bone marrow cell kinetics. This may help to explain why patients frequently have disease relapse even with a negative BMA. It is postulated that a BMA, by its nature, provides either a sample of cells that are in transit or a sample that is removed from the endosteum. The cells in transit may be circulating from the original tumor, or are detached from a proliferating micrometastatic site.

There are no studies of in vivo tumor cell rheology in the bone marrow. However, there are in vivo optical imaging 
Table III. Expression of MMP-2, CD82 and HER-2 in patients according to Gleason score.

\begin{tabular}{|c|c|c|c|c|c|}
\hline & $\begin{array}{c}\text { Gleason } 4 \\
\%(\mathrm{n})\end{array}$ & $\begin{array}{c}\text { Gleason } 5+6 \\
\%(\mathrm{n})\end{array}$ & $\begin{array}{c}\text { Gleason } 7 \\
\%(\mathrm{n})\end{array}$ & $\begin{array}{c}\text { Gleason } 8+9 \\
\%(n)\end{array}$ & $\begin{array}{c}\text { P-value } \\
\text { (statistical test- } \\
\text { log regression) }\end{array}$ \\
\hline Total $100 \%(n=185)$ & $15.1(28)$ & $57.3(106)$ & $16.8 \quad(31)$ & $10.8 \quad(20)$ & \\
\hline CPC-positive $62.7 \%(n=116)$ & 46.4 (13) & $63.2 \quad(67)$ & $64.5 \quad(20)$ & $80.0 \quad(16)$ & NS \\
\hline MMP-2 & $100.0(13)$ & $100.0 \quad(67)$ & $100.0 \quad(20)$ & $100.0 \quad(16)$ & NS \\
\hline CD82 & $61.5^{\mathrm{a}}(8)$ & $1.9^{\mathrm{a}} \quad(2)$ & 0 & 0 & $<0.001^{\mathrm{a}-\mathrm{a}}$ \\
\hline HER-2 & $23.1^{\mathrm{b}, \mathrm{c}}(3)$ & $20.9^{\mathrm{d}, \mathrm{e}}(14)$ & $60.0^{\mathrm{b}, \mathrm{d}}(12)$ & $63.5^{\mathrm{c}, \mathrm{e}}(10)$ & $\begin{array}{l}<0.02^{\mathrm{b}-\mathrm{b}} \\
<0.005^{\mathrm{c}-\mathrm{c}} \\
<0.005^{\mathrm{d}-\mathrm{d}} \\
<0.002^{\mathrm{e}-\mathrm{e}}\end{array}$ \\
\hline DTC-positive $62.5 \%(n=115)$ & $35.7(10)$ & $65.1 \quad(69)$ & $67.7 \quad(21)$ & $75.0(15)$ & \\
\hline MMP-2 & $100.0(10)$ & $100.0 \quad(69)$ & $100.0 \quad(21)$ & $100.0(15)$ & NS \\
\hline CD82 & $79.0^{\mathrm{f}} \quad(7)$ & $4.4^{\mathrm{f}} \quad(3)$ & 0 & 0 & $<0.001^{\mathrm{f}-\mathrm{f}}$ \\
\hline HER-2 & $20.0^{\mathrm{g}, \mathrm{h}}(2)$ & $21.8^{\mathrm{i}, \mathrm{j}}(15)$ & $52.4^{\mathrm{g}, \mathrm{i}}(22)$ & $60.0^{\mathrm{h}, \mathrm{j}}(9)$ & $\begin{array}{l}<0.017^{\mathrm{g}-\mathrm{g}} \\
<0.006^{\mathrm{h}-\mathrm{h}} \\
<0.01^{\mathrm{i}-\mathrm{i}} \\
<0.002^{\mathrm{j}-\mathrm{j}}\end{array}$ \\
\hline MM-positive $71.4 \%(n=132)$ & $32.1(9)$ & $77.4 \quad(82)$ & $77.4(22)$ & $85.0 \quad(17)$ & \\
\hline MMP-2 & $0^{\mathrm{k}-\mathrm{m}}$ & $14.6^{\mathrm{k}, \mathrm{n}}(11)$ & $20.8^{1}(5)$ & $41.1^{\mathrm{m}, \mathrm{n}}(7)$ & $\begin{array}{c}<0.002^{\mathrm{k}-\mathrm{k}} \\
<0.002^{\mathrm{l}-\mathrm{l}} \\
<0.002^{\mathrm{m}-\mathrm{m}} \\
<0.002^{\mathrm{n}-\mathrm{n}} \\
\text { Trend Chi-squared } \\
\mathrm{P}=0.031\end{array}$ \\
\hline CD82 & 0 & 0 & 0 & 0 & \\
\hline HER-2 & $22.2^{\mathrm{o}, \mathrm{p}}(2)$ & $25.6^{\mathrm{q}, \mathrm{r}}(21)$ & $58.3^{\mathrm{o}, \mathrm{q}}(14)$ & $58.8^{\mathrm{p}, \mathrm{r}}(10)$ & $\begin{aligned} & \mathrm{NS} \\
< & 0.004^{\mathrm{o}-\mathrm{o}} \\
< & 0.003^{\mathrm{p}-\mathrm{p}} \\
< & 0.006^{\mathrm{q}-\mathrm{q}} \\
< & 0.006^{\mathrm{r}-\mathrm{r}}\end{aligned}$ \\
\hline
\end{tabular}

MMP-2, matrix metalloproteinase-2; DTC, disseminated tumor cell; CPC, circulating prostate cell; MM, micrometastasis; and NS, not significant.

Table IV. Concordance among detection of CPCs, DTCs and micrometastasis according to Gleason score.

\begin{tabular}{lcccc}
\hline א-values between & Gleason 4 & Gleason 5+6 & Gleason 7 & Gleason 8+9 \\
\hline CPC + DTC & 0.64 & 0.55 & 0.78 & 0.57 \\
CPC + MM & 0.27 & 0.32 & 0.23 & 0.48 \\
DTC + MM & 0.60 & 0.39 & 0.44 & 0.69 \\
\hline
\end{tabular}

kappa-values: 0-0.2, no concordance,;0.21-0.40, low concordance; 0.41-0.60, moderate concordance; 0.61-0.8, good concordance; >0.80, excellent concordance. CPCs, circulating prostate cells; DTCs, disseminated tumor cells; MM, micrometastasis.

studies in laboratory animals demonstrating the mechanisms of tumor cell attachment to the endosteum that are similar to stem cell engraftment $(14,15)$. Topological and chronological patterns of stem cell seeding have shown that most cells drift within the bone marrow space, then are gradually found close to the endosteal surface. The center of the bone marrow space seems to be the site of proliferation of transplanted cells and not the endosteal surface (16). Further studies have shown that the adherent cells are viable, whereas cells in transit contain a percentage of dead or dying cells (17). Experimental data suggest that adhesion is the rate limiting determinant of homing and early seeding and a crucial event that preserves 
Table V. Concordance between CPCs, DTCs and micrometastasis for the expression of MMP-2, CD82 and HER-2.

A, Concordance between the expression of MMP-2 in CPCs, DTCs and micrometastasis according to Gleason score.

\begin{tabular}{lcccc}
\hline kappa: MMP-2 & Gleason 4 & Gleason $5+6$ & Gleason 7 & Gleason 8+9 \\
\hline CPCs + DTCs & 0.64 & 0.59 & 0.78 & 0.57 \\
CPCs + MM & 0 & 0.14 & 0.19 & 0.23 \\
DTCs + MM & 0 & 0.13 & 0.17 & 0.30 \\
\hline
\end{tabular}

B, Concordance between the expression of CD82 in CPCs, DTCs and micrometastasis according to Gleason score.

\begin{tabular}{lcc}
\hline kappa: CD82 & Gleason 4 & Gleason $5+6$ \\
\hline CPCs + DTCs & 0.55 & 0.80 \\
CPCs + MM & 0 & 0 \\
DTCs + MM & 0 & 0 \\
\hline
\end{tabular}

C, Concordance between the expression of HER-2 in CPCs, DTCs and micrometastasis according to Gleason score.

\begin{tabular}{lcccc}
\hline kappa: HER-2 & Gleason 4 & Gleason $5+6$ & Gleason 7 & Gleason 8+9 \\
\hline CPCs + DTCs & 0.78 & 0.88 & 0.93 & 0.90 \\
CPCs + MM & 0.78 & 0.69 & 0.87 & 0.80 \\
DTCs + MM & 1.00 & 0.67 & 0.80 & 0.90 \\
\hline
\end{tabular}

kappa-values: 0-0.2, no concordance; 0.21-0.40, low concordance; 0.41-0.60, moderate concordance; 0.61-0.8, good concordance; $>0.80$, excellent concordance. CPCs, circulating prostate cells; DTCs, disseminated tumor cells; MM, micrometastasis; and MMP-2, matrix metalloproteinase- 2 .

Table VI. Type of dissemination defined by the presence of CPCs, DTCs and micrometastasis.

\begin{tabular}{|c|c|c|c|c|c|c|}
\hline & All negative & $\begin{array}{c}\text { CPCs (+) } \\
\text { DTCs (-) } \\
\text { MM (-) }\end{array}$ & $\begin{array}{c}\text { CPCs (+) } \\
\text { DTCs (+) } \\
\text { MM (-) }\end{array}$ & All positive & $\begin{array}{c}\text { CPCs (-) } \\
\text { DTCs (+) } \\
\text { MM (+) }\end{array}$ & $\begin{array}{l}\text { CPCs (-) } \\
\text { DTCs (-) } \\
\text { MM (+) }\end{array}$ \\
\hline All patients $(n=185)$ & 36 & 6 & 13 & 94 & 16 & 20 \\
\hline Patients with BF $(n=115)$ & 20 & 1 & 7 & 60 & 11 & 16 \\
\hline Classification & None/local & $\begin{array}{c}\text { Local with } \\
\text { dissemination }\end{array}$ & $\begin{array}{l}\text { Local with } \\
\text { dissemination }\end{array}$ & $\begin{array}{l}\text { Systemic with } \\
\text { dissemination }\end{array}$ & $\begin{array}{l}\text { Systemic with } \\
\text { dissemination }\end{array}$ & Systemic \\
\hline
\end{tabular}

CPCs, circulating prostate cells; DTCs, disseminated tumor cells; MM, micrometastasis; BF, biochemical failure.

the viability of cells towards successful engraftment (17). The fact that cells attached to the endosteal surface are not usually detected may explain why all patients with positive BMA do not develop metastasis. Conversely, patients with negative BMA may have cancer cells attached to the endosteal surface that may eventually develop into metastasis. Thus, in high-grade cancer, the interchange between cells between the bone and intertrabecular space may be sufficiently high, suggesting that the presence of DTCs is equivalent to the presence of micrometastasis. However in intermediate grade cancer, with a lower interchange rate this relationship does not appear to remain valid. However, this would not explain why there was good concordance between the presence of DTCs and micrometastasis in low-grade Gleason 4 cancer. The concordance was confined to patients with stage 3 disease. These patients experienced biochemical failure, had MMP-2negative micrometastasis and CPCs and DTCs were detected. One explanation is that the CPCs and DTCs originated from a local failure near to the prostate bed and the micrometastasis was in a dormant state in the bone marrow. This needs to be further investigated with a larger group of patients.

Phenotypically CPCs and DTCs were identical, but differed from micrometastasis. The lack of CD82 expression in micrometastasis suggests that the expression of this tumor-suppressor protein present in low-grade tumors inhibits implantation of CPCs (CPCs and DTCs), as was suggested previously (18). HER-2 expression increased significantly with an increasing Gleason score, without significant differences between CPCs, 
DTCs and micrometastasis. This is explained by the fact that men with androgen blockade had higher Gleason scores as was previously reported (19).

The differential expression of MMP-2 may explain in part the differences in the concordance among CPCs, DTCs and micrometastasis. The differential expression of MMP-2 in bone marrow micrometastasis, where the absence of MMP-2 detected by immunocytochemistry is common, suggests the inhibition of MMP-2. The stromal microenvironment plays a critical role in determining tumor cell behavior in primary tumors; the stromal cells increasing MMP-2 expression in tumor cells $(20,21)$. To the best of our knowledge, we describe for the first time in prostate cancer that bone marrow stromal cells produce the opposite reaction, that of inhibition of MMP-2 expression. That the expression is different to that in CPCs and DTCs, is supportive evidence that prostate cells detected in BMAs are different and are not true micrometastasis (7), but represent circulating tumor cells in the bone marrow compartment. It has been shown that the bone marrow microenvironment is composed of specific niches that provide support for the proliferation and maintenance of hematopoietic stem cells (22). Interactions between the stem cells and their microenvironment regulate their maintenance, proliferation, differentiation and migration into the blood circulation. Distinct niches have been anatomically and physiologically defined within the bone marrow $(23,24)$. In the endosteal region, osteoblasts and other mesenchymal derived stromal cells such as reticular cells, fibroblasts and adipocytes constitute the osteoblastic niche that supports the maintenance of hematopoietic stem cells in a quiescent and undifferentiated state, by adhesion and humoral factors (25).

We propose that the expression of MMP-2 is inhibited by bone marrow stromal cells, in a process similar to that noted in hematopoietic stem cells, possibly by TIMP-2. Other inhibitors modulating this function cannot be excluded.

The inhibition of MMP-2 decreases the ability of cancer to migrate from its new site, but does not inhibit proliferation directly. However, the decreased release of growth factors produced by MMP-2 and decreased initiation of angiogenesis by MMP-9 induced in part by MMP-2 (26) may limit the growth potential of microfoci. However, in high-grade cancer, such as Gleason 9, tumor cells of the micrometastasis continue to proliferate. As they divide and expand towards the intertrabecular surface, the inhibition by stromal cells decreases. This permits the reappearance of MMP-2 expression, as noted in the microfragment borders but not in the centre of the fragment, where MMP-2 suppression continues. This in turn allows the cells to escape and to disseminate, forming 2 CPCs. This theory would explain our results demonstrating the concordance between DTCs and micrometastasis for Gleason scores 5-9.

Using the presence of conventional DTCs rather than micrometastasis as a biomarker for systemic disease and to indicate systemic treatment after biochemical failure, $20 \%$ of patients would be erroneously classified.

Thus, this study suggests that DTCs in intermediate grade cancer do not indicate micrometastasis and are simply circulating tumor cells in the bone marrow compartment. They are phenotypically different and if used to define systemic micrometastatic disease misclassification of patient would occur in
$20 \%$ of the cases. Due to the phenotypic differences, various treatments may be necessary in order to eliminate DTCs, particularly when considering targeted therapy.

\section{Acknowledgements}

We gratefully thank Mrs. Ana Maria Palazuelos for her assistance in this study.

\section{References}

1. NCCN prostate cancer guidelines 2012. Accessed www.nccn2012. org.

2. Freedland SJ, Sutter ME, Dorey F and Aronson WJ: Defining the ideal cutpoint for determining PSA recurrence after radical prostatectomy: prostate specific antigen. Urology 61: 365-369, 2003.

3. Wood DP and Banerjee M: Presence of circulating prostate cells in the bone marrow of patients undergoing radical prostatectomy is predictive of disease free survival. J Clin Oncol 15: 3451-3457, 1997.

4. Cher ML, De Oliveira JG, Beaman AA, Nemeth JA, Hussain M and Wood DP Jr: Cellular proliferation and prevalence of micrometastatic cells in the bone marrow of patients with clinically localized prostate cancer. Clin Cancer Res 5: 2421-2425, 1999.

5. Oberneder R, Riesenberg R, Kreigmair M, et al: Immunocytochemical detection and phenotypic characterization of micrometastatic tumor cells in bone marrow of patients with prostate cancer. Urol Res 22: 3-8, 1994.

6. Pantel K, Aignherr C, Kollermann J, Caprano J, Riethmuller G and Kollermann MW: Immunocytochemical detection of isolated tumor cells in bone marrow of patients with untreated stage C prostate cancer. Eur J Cancer 31: A1627-A1632, 1995.

7. Murray NP, Calaf GM and Badinez L: Presence of prostate cells in bone marrow biopsies as a sign of micrometastasis in cancer patients. Oncol Rep 21: 571-575, 2009.

8. Bearden JD, Ratkin GA and Coltman CA: Comparison of the diagnostic value of bone marrow biopsy and bone marrow aspiration in neoplastic disease. J Clin Pathol 27: 738-740, 1972.

9. Bjorneklett A, Slavern P and Elgio K: Relative value of sterna aspiration, iliac crest biopsy and biopsy imprint in the diagnosis of secondary cancer involvement of the bone marrow. Acta Med Scand 203: 279-281, 1978.

10. Moid F and DePalma L: Comparison of relative value of bone marrow aspirates and bone marrow trephine biopsies in the diagnosis of solid tumor metastasis and Hodgkin lymphoma. Arch Pathol Lab Med 129: 497-501, 2005.

11. Borgen E, Naume B, Nesland JM, Kvalhein E, Beiske K, Fodsted O, et al: Standardization of the immunocytochemical detection of cancer cells in bone marrow and blood: I. establishment of objective criteria for the evaluation of immunostained cells. Cytotherapy 5: 377-388, 1999.

12. Trudel D, Fradet Y, Meyer F, Harel F and Tetu B: Significance of MMP-2 expression in prostate cancer. Cancer Res 63: 8511-8515, 2003.

13. Osman I, Scher HI, Drobnjak M, Verbel D, Morris M, Agus D, et al: HER-2/neu (p185neu) protein expression in the natural or treated history of prostate cancer. Clin Cancer Res 7: 2643-2647, 2001.

14. Askenasy N and Farkas DL: Optical imaging of PKH-labeled hematopoietic cells in recipient bone marrow in vivo. Stem Cells 20: 501-513, 2002.

15. Quesenberry PJ and Becker PS: Stem cell homing: rolling, crawling and nesting. Proc Natl Acad Sci USA 95: 15155-15157, 1998.

16. Christensen JL, Wright DE, Wagers AJ and Weissman IL: Circulation and chemotaxis of fetal hematopoietic stem cells. PLoS Biol 2: E75, 2004

17. Mazo IB and Von Andrian UH: Adhesion and homing of bloodborne cells in bone marrow microvessels. J Leukoc Biol 66: 25-32, 1999.

18. Murray NP, Badínez L, Badínez O, Orellana N, Dueñas R, Reyes E and Fuentealba C: Expresión del supresor tumoral CD82 en células prostáticas primarias y secundarias en la circulación sanguínea (CPCs) de pacientes con cáncer prostático. Rev Mex Urol 70: 92-96, 2010 (In Spanish). 
19. Murray NP, Badinez L, Dueñas R, Orellana N and Tapia P: Positive HER-2 protein expression in circulating prostate cells and micro-metastasis, resistant to androgen blockage but not diethylstilbestrol. Indian J Urol 27: 200-207, 2011.

20. Chung LW, Baseman A, Assikis V and Zhau HE: Molecular insights into prostate cancer progression: the missing link of tumor microenvironment. J Urol 173: 10-20, 2005.

21. Sato T, Sakai T, Noguvhi Y, Takita M, Hirakawa S and Ito A: Tumor stromal cell contact promotes invasion of human cervical carcinoma cells by augmenting the expression and activation matrix metalloproteinases. Gynecol Oncol 92: 47-56, 2004.

22. Heissig B, Ohki Y, Sato Y, Rafii S, Werb Z, and Hattori K: A role for niches in hematopoietic cell development. Hematology 10: 247-253, 2005 .
23. Yaniv I, Stein J, Farkas DL and Ashenasy N: The tale of early hematopoietic cell seeding in the bone marrow niche. Stem Cells Dev 15: 4-16, 2006.

24. Kaplan RN, Psaila B and Lyden D: Niche to niche migration of bone marrow derived cells. Trends Mol Med 13: 72-81, 2007.

25. Taichmann RS: Blood and bone: two tissues whose fates are intertwined to create the hematopoietic cell stem niche. Blood 105: 2631-2639, 2005

26. Bergers G, Brekken R, McMahon G, Vu TH, Itoh T, Tamaki K, et al: Matrix metalloproteinase- 9 triggers the angiogenic switch during carcinogenesis. Nat Cell Biol 2: 737-744, 2000. 